Research Article

\title{
Effectiveness of Pranayam Techniques in Reduction of Stress among Old Age People at Selected Rural Community at Bhopal
}

\author{
Venice Mariya David
}

Professor, Chirayu College of Nursing, Bhopal, Madhya Pradesh.

DOI: https://doi.org/10.24321/2348.2133.201908

\section{I $\quad \mathbf{N} \quad \mathbf{F} \quad \mathbf{O}$}

\section{E-mail Id:}

veniceanoop@gmail.com

\section{Orcid Id:}

https://orcid.org/0000-0002-1750-7735

How to cite this article:

David VM. Effectiveness of Pranayam Techniques in Reduction of Stress among Old Age People at Selected Rural Community at Bhopal. Ind J Holist Nurs 2019; 10(2\&3): 16-19.

Date of Submission: 2020-04-09

Date of Acceptance: 2020-04-28

\section{$\begin{array}{lllllllllll}\mathbf{A} & \mathbf{B} & \mathbf{S} & \mathbf{T} & \mathbf{R} & \mathbf{A} & \mathbf{C} & \mathbf{T}\end{array}$}

Introduction: Emergent old in a society that has been obsessed with youth may have a critical impact on the mental health of many people. Older people may face worsening health or dwindling finances or simply the challenges of retaining their independence. Unfortunately, the body's natural defenses against stress gradually break down with age. Psychological stress has frequently been associated with a broad spectrum of negative health outcomes Although life after the retirement age is generally considered to be a peaceful period of life, many psychological challenges, such as loneliness, bereavement, caring for a family member and deterioration of own health, may occur, all of which can lead to increased levels of stress. Due to prolonged life expectancy, more and more adults are reaching very old age, increasing the possibility to face health-related stressors consequently leading to higher levels of perceived stress.

Objective: To evaluate the effectiveness of pranayama in reduction of stress among old age people.

Methodology: The researcher used.pre experimental research design with evaluative approach used, setting of the study was Apna Old Age Home, Bhopal and sample size comprises of 30 old age people residing in old age homes.

Result: The present finding of the study indicate that in pretest majority $20(66.67 \%)$ of old age people had high perceived stress, $7(23.33 \%)$ had moderate stress, and 3 (10.\%) had low stress. In Post-test: Majority $25(83.33 \%)$ of old age people had moderate stress and 2 (16.66\%) had low stress and none of having high level of stress perceived after doing pranayama.

Conclusion: pranayama is a very cheap and cost effective in reduction of various psychological problems without having any side effect.

Keywords: Old Age People, Stress, Pranayama 


\section{Background of the Study}

Old age is an emergent population that has been increasing in the society and may have a critical impact on the mental health of many old age people due to concept of the nuclear family, the burden on the family, dependence on their children; these causes psychological problems. ${ }^{1}$ Stress is a part of life, old age people have faced many problems and various situations and overcome challenges. Older people may face failing health or dwindling finances or simply the challenges of retaining their independence. Unfortunately, the body's natural defenses against stress gradually break down with age. On the other hand, many seniors still manage their later years. ${ }^{1}$ Emotional stress is more understated, and if it is chronic, the ultimate consequences can be as harmful. Stress hormones (cortisol and adrenaline) provide energy and focus in the short term, but too much stress over too many years can throw a person's system off balance. Excess of stress hormone has been associated with numerous health problems, including heart disease, high blood pressure, and weakened immune functions. For older people already at heightened risk for these illnesses, managing stress is primarily essential.

Psychological stress has frequently been associated with a broad spectrum of negative health outcomes. Although life after the retirement age is generally considered to be a peaceful period of life, many psychological challenges, such as loneliness, bereavement, caring for a family member and deterioration of own health, may occur, all of which can lead to increased levels of stress. Due to increased life expectancy of the people, many health problems exist among old age people; they may persistently face healthrelated psychological problems like depression, stress and anxiety because of dependency on children, ignorance, abuse, nuclear families, etc. ${ }^{2}$

\section{Need for the Study}

In India, the elderly population above 60 years was 1 crore and 20 lakhs in 1901, 2 crores in 1950, 5 crores in 1991 and will be 10 crores in 2013 that makes $10 \%$ of the total population. In India, it has been reported that at present there are 77 million elderly people and the number is expected to be 177 million in the next 2 and half decades, respectively. In India life expectancy at birth has increased by 20 years in the past 5 decades. The average life span today is 66 years. Today there are about 77 million people in India aged above 60 years. ${ }^{3}$

Stress is a complex factor that generates social and psychological problems for the individual and thus for society. ${ }^{4}$ Adaptation to aging is critical to one's happiness; failure to adapt can result in stress. Adaptive coping will alter may be seriously due to major stressors like financial problems, physical illness, change in body functioning, increased awareness of approaching death, and numerous losses of individual experiences during the period of life. ${ }^{4}$ The old-age population suffers both physical as well as mental changes in life like biological or bodily changes, loss of a partner, change in family structure and role, economic dependency, all of which contribute to the mental health problems. Many studies have been done on the different type of problems faced by old age people like physical, psychological, social and financial but still there is an increasing number of old age homes day by day. Old age people have some level of stress and they were not taking any measures to avoid that, as per the knowledge of investigators no studies done related to the nursing interventions in the reduction of stress among elderly. The investigator as a student and clinical instructor had the opportunity to care for the elderly in old age homes. During my community posting, I have seen many old age people who are suffering from various problems like physical, socialpsychological problems due to the high cost of treatment people are unable to afford the medicine. ${ }^{5}$

\section{Research Methodology}

The objectives include assessment of the level of stress among old age people, the effectiveness of pranayama in decreasing stress among old age people by comparing pretest and post test score and to established the association between pre-test levels of stress with their selected demographic variables.

\section{Hypothesis}

$\mathbf{H}_{1}$ : There will be the mean posttest stress score higher than the mean pre-test stress score among old age people after administering of pranayama at $\mathrm{P}>0.05$ level of significance.

$\mathbf{H}_{\mathbf{0}}$ : There will be no significant association between the pretest stress score with their selected demographic variables at $\mathrm{P}>0.05$ level of significance.

The evaluative research approach and Pre-experimental one group pretest posttest research design were adopted. The study was conducted at Bhouri (Neelbud) rural community at Bhopal. Total 30 samples were selected using nonprobability purposive sampling technique.

\section{Sampling Criteria}

Inclusion Criteria: The old age people who were above 50 years of age in both sexes and willing to participate and present at the time of data collection.

Exclusion Criteria: The old age people who were physically weak and had psychological problems and restricting physical activity.

Tool: The section of tool was divided in 2 sections: (1) Baseline information, age in year, gender qualification, marital status, religion, occupation, duration of medical 
illness, any medical illness present, monthly income. ${ }^{2}$ Perceived stress scale (PPS) was used to assess the level of stress among old age people. The reliability of the tool was found 0.78 by using internal consistency reliability analysis through Cronbach's alpha.

Data Collection Procedure: Prior permission was obtained by the Apna Old Age Home, Bhopal and from the subjects. The investigator used self-structured knowledge questionnaire for data from the samples. The duration of the study was 4 weeks.

Data Analysis Plan and Presentation: Descriptive statistics and inferential statistics such as mean, percentage and standard deviation chi-square and paired T test were used. ${ }^{6}$

\section{Result and Discussion of the Study}

Section 1: Findings related to frequency and percentage distribution of demographic variables of old age people; In the elderly people $40 \%$ were in the age group of 60 to 65 years, $30 \%$ male and $70 \%$ female in the gender, $70 \%$ were having primary education, $70 \%$ were Widowed/widower, 40\% were Hindu, 30\% were having their business, $60 \%$ were having less than 5000/- monthly income, 60\% were labour and $70 \%$ were having medical problems like DM, HTN, asthma, renal failure and backache, and $50 \%$ were having duration of medical illness more than 5 year.

Section 2: Findings related to Pre-test and post-test level of stress among old age people. This section describes the Perceived stress scale scores of old people residing in Neelbud rural community at Bhopal before and after the administration of Pranayama.

Table I.The effectiveness of pranayama in reduction of stress among old people in terms of frequency and percentage (Pre-test \& Post-test)

\begin{tabular}{|c|c|c|c|c|c|}
\hline \multirow{2}{*}{ Level of stress } & \multirow{2}{*}{ Scoring } & \multicolumn{2}{|c|}{ Pre-test } & \multicolumn{2}{|c|}{ Posttest } \\
\cline { 3 - 6 } & $\mathbf{F}$ & $\%$ & $\mathbf{F}$ & $\%$ \\
\hline High level of stress & $27-40$ & 20 & 66.67 & 0 & 0 \\
\hline $\begin{array}{c}\text { Moderate level of } \\
\text { stress }\end{array}$ & $14-26$ & 7 & 23.33 & 25 & 83.33 \\
\hline Low level of stress & $0-13$ & 3 & 10 & 5 & 16.66 \\
\hline
\end{tabular}

\section{Comparision of pre-test and post-test level of stress}

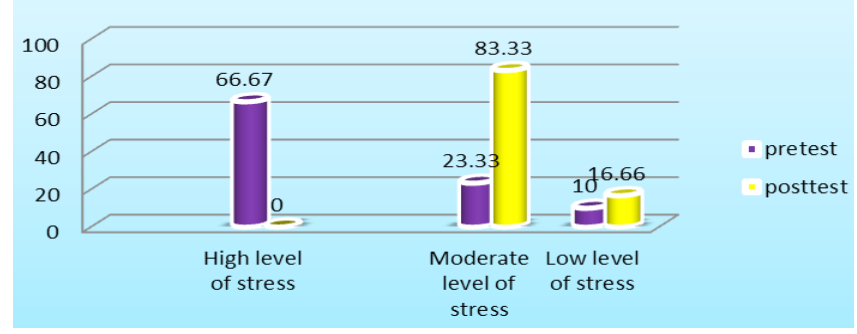

Pre-test: The data presented in the Table 1 reveals that, in pretest, majority $20(66.67 \%)$ of old age people had high level of stress, 7 (23.33\%) had moderate level of stress, and $3(10 . \%)$ had low level of stress. In Post-test: Majority 25 (83.33\%) of old age people had moderate level of stress and $2(16.66 \%)$ had low level of stress and none high level of stress perceived after doing pranayam. Hence, the hypothesis $\mathrm{H}_{1}$ was accepted.

The Table 2, indicates that mean score of pre-test is 24.10 with standard deviation 8.20 and the mean score of post-test is 16.24 with standard deviation 3.10. The mean difference was found to be 7.86. The obtained mean difference " $\mathrm{t}$ " value is 2.41 which is greater than table value 2.0452 for df (29) at p> 0.05 level of significance which is higher than the table value. Hence, the hypothesis made by the researcher was accepted.

Table 2.Mean, mean difference standard deviation and " $t$ " value of old age people before and after administration of pranayama

\begin{tabular}{|c|c|c|c|c|c|c|}
\hline Tests & mean & $\begin{array}{l}\text { mean } \\
\text { diffe- } \\
\text { rence }\end{array}$ & $\begin{array}{l}\text { standard } \\
\text { deviation }\end{array}$ & Df & $\begin{array}{c}\mathrm{t} \\
\text { value }\end{array}$ & $\begin{array}{l}\text { interf- } \\
\text { erence }\end{array}$ \\
\hline $\begin{array}{l}\text { pre- } \\
\text { test }\end{array}$ & 24.10 & \multirow[b]{2}{*}{7.86} & 8.20 & \multirow[b]{2}{*}{29} & \multirow[b]{2}{*}{$2.41 *$} & \multirow{2}{*}{$\begin{array}{c}\text { table } \\
\text { value } \\
2.045 \\
\text { at } \\
\text { p }>0.05\end{array}$} \\
\hline $\begin{array}{l}\text { post- } \\
\text { test }\end{array}$ & 16.24 & & 3.10 & & & \\
\hline
\end{tabular}

Section 3: Association of post-test score with the selected demographic variables by using chi-square: It was marked from the obtained chi square values that there was no significant association between the pre-test stress score with selected demographic variables like age, gender, education, marital status, religion, duration of medical illness, medical illness present, monthly income, occupation. Hence $\mathrm{H}_{2}$ hypotheses made by the investigator was rejected

\section{Discussion}

The results of the study show that in pretest maximum $20(66.67 \%)$ of old age people had high level of stress, $7(23.33 \%)$ had moderate level of stress and $3(10 . \%)$ had low level of stress. In Post-test: Maximum 25 (83.33\%) of old age people had moderate level of stress and 2 (16.66\%) had low level of stress and none of having high level of stress after doing pranayam. In another study the result showed that there was a significant decrease in depression score and improved quality-of-life after practicing yoga. (Pre-test score HAD WHO QOL-7.88 (SD=3.86. post test score HAD WHO QOL -1.6 SD=5.72 P<0.002). ${ }^{7}$

Another supportive study by Vivek Sharma 2013: study was conducted to compare the effects of commonly 
practiced slow and fast pranayama on perceived stress and cardiovascular functions in young health-care students. There was a significant decrease in PSS scores in both Group Significant decrease in HR, DBP, RPP, and Do $P$ was seen in only Group 2 subjects. This study demonstrates that both types of pranayama practice are beneficial in reducing PSS in the healthy subjects but beneficial effect on cardiovascular parameters occurred only after practicing slow pranayama

\section{Conclusion}

The results of the study proved that after doing pranayam $83.33 \%$ had moderate stress in post-test among old age people. Therefore, Pranayama expanding your breath for several minutes have a surprisingly positive influence on energy level or mood. It multiply effect significantly by using pranayama-breathing exercises tailored to have an effect on specific moods and conditions. Based on knowledge cultivated and refined by the yogis, these exercises intentionally alter the speed, rhythm, and space of the breath which helps to the remove negative thoughts and reduce the level of stress and improve the psychological wellbeing.

\section{Recommendation of the Study}

- $\quad$ Similar study can be done on larger sample for improving to generalize the finding to a large population.

- Comparative study can be done between the male and female elderly people residing in old age home and joint family with different relaxation techniques.

- A true experimental approach can be used in another large setting with different intervention.

\section{Conflicts of Interest: None}

\section{References}

1. Anoop A. The ageing individual. Nightingale nursing times 2005; 1(8): 57.

2. Shree P. A study to assess the effectiveness of pranayama in reduction of stress among senior citizens. International Journal of Applied Research 2016; 2(6): 940-941.

3. World Health Organization, Geneva, Sixty- World Health Assembly, Comprehensive mental health. Action plan 2013-2020, A66/70, 24 May 2013.

4. Potter - Perry. Fundamentals of nursing. $\left(6^{\text {th }} \mathrm{ed}\right)$. Missouri: Mosby publication. 2005.

5. Shivini R. Text Book of Psychiatry Nursing", $(2$ ed. $)$. New Delhi: Jaypee brothers. 2009.

6. DF Polit et.al.,(2008). Nursing research generating \& Asserting evidence for nursing practice $(8$ ed). New Delhi: wolters Kluwer's pvt. Ltd.

7. Hariprasad VR, Siva Kumar PT, Koparde V, Varambally S, Thirthalli J, Varghese $M$ et al. Effects of yoga intervention on sleep and quality-of-life in elderly: A randomized controlled trial. Indian J Psychiatry 2013; 55(Suppl 3): S364-S368. 